\title{
The role of the gynaecologist in the promotion and maintenance of oral health during pregnancy
}

\author{
Angelika Kobylińska ${ }^{1}$, Nicole Sochacki-Wójcicka ${ }^{2}$, Natalia Dacyna ${ }^{3}$, Magdalena Trzaska ${ }^{3}$, \\ Anna Zawadzka ${ }^{3}$, Dariusz Gozdowski ${ }^{4}$, Mirosław Wielgoś ${ }^{2}$, Dorota Olczak-Kowalczyk ${ }^{1}$ \\ ${ }^{1}$ Department of Paediatric Dentistry, Medical University of Warsaw, Poland \\ ${ }_{2}^{2}{ }^{\text {st }}$ Clinic and Department of Obestrics and Gynecology, Medical University of Warsaw, Poland \\ ${ }^{3}$ Student's Scientific Club, Department of Paediatric Dentistry, Medical University of Warsaw, Poland \\ ${ }^{4}$ Department of Experimental Design and Bioinformatics, Faculty of Agriculture and Biology, \\ Warsaw University of Life Sciences, Warsaw, Poland
}

\begin{abstract}
Objectives: The aim of the study was to assess routine dental examination attendance of pregnant women and a possible impact of gynaecological referrals on the attendance rate.

Material and methods: An electronic survey was conducted that was inclusive of women up to 5 years following delivery. The questions related to socio-demographic data, the course of pregnancy and childbirth, and visits to dental office during pregnancy. For statistical analysis, the authors utilized the chi-square test, Spearman's rank correlation coefficient and odds ratios. A significance level of 0.05 has been assumed.

Results: A total of 3455 questionnaires were analyzed encompassing women aged 13.1-45.4 years. The respondents were on average $1.78 \pm 1.44$ years after childbirth. The population comprises of women in $59.1 \%$ from large cities, in $74.8 \%$ with higher education and in $41 \%$ with good socio-economic status. A total of $62.3 \%$ of women from the study population have visited a dentist for a routine dental examination. Gynaecologists have given a simple referral to a dentist to $17.6 \%$ of all women. $45.9 \%$ of them were further requested to provide back the feedback of their dental consultation. Dental appointments were upheld by $87.3 \%$ of referred women and by $56.9 \%$ of those without a referral $(O R=5.20(4.05-6.67) ; p<0.001)$. Among those who were referred, dental appointments were upheld in $91.7 \%$ of cases when further asked to provide oral health feedback and in $83.5 \%$ of cases in absence of such further request $(O R=2.19(1.3-3.66) ; p=0.003)$.

Conclusions: It was determined that referrals from a gynaecologist, and associated oral health feedback requests increase the frequency of abiding to dental appointments during pregnancy. As such, it is necessary to increase the involvement of gynaecologists in the promotion and maintenance of perinatal oral health.
\end{abstract}

Key words: oral health, pregnancy, dental care attendance, gynaecologists

Ginekologia Polska 2018; 89, 3: 120-124

\section{INTRODUCTION}

Oral cavity diseases, especially those infectious in nature, affect negatively not only the process of pregnancy and delivery but also the overall health of the offspring, including the condition of child's teeth [1]. Clinical studies have shown that advanced periodontal disease increases the risk of premature birth and low birth weight [2]. High concentrations of PGE2 in the mother's gingival fluid, accompanied by periodontitis, may even be considered a predictor of premature birth $[3,4]$.

Offenbacher et al. observed a lower preterm birth rate in women with a healthy periodontium (1.1\%) compared to women with mild (3.5\%) and/or advanced periodontitis (11.1\%). The authors also noted that infants with a birth weight below $1000 \mathrm{~g}$ occurred only in the group of women with periodontitis [5]. These observations have been 
confirmed by other researchers [6, 7]. It has also been shown that the treatment of periodontal inflammation reduces the risk of preterm birth and low birth weight, as well as other complications during pregnancy [8].

The condition of the mother's dentition is one of the most influential factors determining the health of the child's teeth. The main etiologic factors are the presence of cariogenic bacteria in the baby's oral cavity and exposure to sugars which are processed into acids [9]. It has been shown that the source of caries-related bacterial infections are caregivers, mainly mothers [10-12]. The higher the level of these bacteria present in the mother's oral cavity, and the more often they will be transferred on to the baby, the greater the risk of developing carious lesions in the baby [13-16]. The indicator that determines a high level of cariopathogens is the presence of active, untreated caries in the pregnant woman $[14,15,17]$.

Unfortunately, changes that occur in the body of a pregnant woman (hormonal and immunological) and the quantity and quality of saliva, increase the risk of oral disease. It has been proven that the increase in hormone levels during pregnancy is conducive to periodontal disease [1].Therefore, it is necessary to reinforce the importance of prevention and dental treatment.

The standards of medical procedures in health care services in the context of perinatal care for a woman during her physiological pregnancy, physiological childbirth and puerperium include the promotion of a healthy lifestyle. That includes oral health check-ups by a doctor or midwife and routine dental examinations that aim at assessing oral health and defining preventive or therapeutic needs as well as establishment of a treatment plan. It should also be emphasized that women during pregnancy and the postpartum period in Poland are entitled to a greater range of medical and preventive procedures as part of benefits reimbursed by the National Health Fund. These accepted systemic solutions enable regular dental examinations and the necessary preventive measures and therapeutic procedures.

The aim of the study was to assess routine dental examination attendance of pregnant women and a possible role of gynaecologists in affecting the attendance rate.

\section{MATERIAL AND METHODS}

An anonymous electronic questionnaire was conducted among women after pregnancy, with deliveries occurring within 5 years from completion of the questionnaire. The study was conducted in April and May 2017. The questionnaire pertaining to pregnancy was evaluated by the Bioethics Committee of Medical University of Warsaw (agreement $\mathrm{KB} / 93 / 2015$ dated 5/5/2015). The questionnaire included questions about the age of the woman, the place of residence (large city, small town and village), education level, family economic situation, occupational activity, pregnancy and childbirth (concomitant diseases, term of delivery, method of delivery), dental care during pregnancy and the reasons for making an appointment to the dentist. Questionnaires completed incorrectly or not completely were excluded.

The obtained data was analyzed using the chi-square test and correlation analysis was obtained using Spearman's correlation coefficient. In addition, for selected categorical variables, odds ratios (ORs) were calculated with confidence intervals. The analyses were carried out in the Statistica 12 (Statsoft) program. A significance level of 0.05 was accepted.

\section{RESULTS}

Among the 3455 completed questionnaires, 3439 were included in the final analysis. Surveys were completed between 2 weeks and 5 years following the delivery (average of $1.78 \pm 1.44$ years). Age of women on the day of delivery ranged from 13 to 43 years (average age $26.79 \pm 4.06$ years), age during the survey ranged from 13.1 to 45.4 (mean age $28.84 \pm 4.04$ ). The socio-demographic characteristics of the study group are presented in Table 1. In the case of 2524 (73.4\%) women it was their first pregnancy. 1019 (29.6\%) of the respondents had their pregnancy complicated with systemic diseases such as thyroid disease (18.17\%), hypertension (8.5\%) and diabetes (7.7\%). The risk of preterm birth occurred in $16.1 \%$ of all cases. Delivery occurred on time in $92.9 \%$ of women, mostly as a result of spontaneous labour (61.8\%).

\begin{tabular}{l}
$\begin{array}{l}\text { Table 1. Socio-demographic characteristics of the surveyed } \\
\text { women }\end{array}$ \\
\hline Parameter \\
\hline
\end{tabular}


A total of $62.3 \%$ of women visited the dentist during their pregnancy. A referral from the gynaecologist was received by $17.6 \%$ of respondents. A gynaecologist, beyond a mere referral, required a feedback from the dentist in $8.4 \%$ of all cases. The Spearman correlation analysis revealed a statistically significant impact of socio-demographic factors on dental care, but this significance was lower with a referral from a gynaecologist (Tab. 2). No significant correlations were found with factors related to pregnancy, parity or delivery. The frequency of visits to a dental clinic, according to the place of residence, economic situation, educational level and occupational activity during pregnancy, are presented in Table 3.

Women referred by their gynaecologist for a dental examination attended visits more frequently than those who did not receive a referral (Tab. 4). A referral to the dentist

Table 2. Spearman correlation coefficients depicting the relationship between the use of dental care during pregnancy and socioeconomic parameters

\begin{tabular}{|l|l|l|l|}
\hline Socio-demographic factor & Total & \multicolumn{2}{c|}{ Referral from a gynaecologist } \\
\cline { 2 - 3 } & & yes & 0.059 \\
\hline Age & & $0.102^{*}$ & $0.110^{*}$ \\
\hline Place of residence (city) & $0.065^{*}$ & -0.039 & $0.076^{*}$ \\
\hline Level of education & $0.090^{*}$ & 0.052 & $0.098^{*}$ \\
\hline Financial situation & $0.076^{*}$ & $0.086^{*}$ & $0.078^{*}$ \\
\hline Professional activity & $0.068^{*}$ & $0.097^{*}$ & $0.062^{*}$ \\
\hline
\end{tabular}

*statistically significant correlations $(P<0.05)$

Table 3. The frequency of pregnant women reporting to dentists in relation to socio-demographic parameters

\begin{tabular}{|c|c|c|}
\hline \multicolumn{2}{|c|}{ Socio-demographic factor } & Women who had a dental appointment during pregnancy $n(\%)$ \\
\hline \multirow{3}{*}{ Place of residence } & village & $534 / 911(58.6 \%) *(p<0.001)$ \\
\hline & small town & $680 / 1122(60.6 \%)^{y(p<0.005)}$ \\
\hline & big city & $928 / 1406(66.0 \%)^{* y}$ \\
\hline \multirow{2}{*}{ Age } & $\leq 25$ & $736 / 1304(56.4 \%) *(p<0.001)$ \\
\hline & $\geq 26$ & $1406 / 2135(65.9 \%)^{*}$ \\
\hline \multirow{2}{*}{ Education } & higher/incomplete higher & $1666 / 2574(64.7 \%)^{*(p<0.001)}$ \\
\hline & secondary and elementary education & $476 / 865(55.0 \%)$ \\
\hline \multirow{3}{*}{ Financial situation } & insufficient & $167 / 316(52.8 \%)^{*(p<0.001)}$ \\
\hline & sufficient & $1044 / 1713(60.9 \%)^{y(p<0.003)}$ \\
\hline & good or very good & $931 / 1410(66.0 \%)^{* y}$ \\
\hline \multirow{2}{*}{ Professional activity } & working & $1758 / 2750(63.9 \%)^{*(p<0.001)}$ \\
\hline & not working & $384 / 689(55.7 \%)^{*}$ \\
\hline
\end{tabular}

*statistically significant correlations $p \leq 0.05$

Table 4. The use of dental care by pregnant women, including gynaecological referral to the dentist and feedback request

\begin{tabular}{|l|c|c|c|c|}
\hline \multirow{2}{*}{ Gynaecologist participation } & & Total & \multicolumn{2}{|c|}{ Dental appointment } \\
\cline { 3 - 5 } & & & yes & no \\
\cline { 3 - 5 } & & & $50)$ & $77 / 606(12.7)$ \\
\hline \multirow{2}{*}{ Referral to the dentist } & yes & $606 / 3439(17.6)$ & $529 / 606(87.3)$ & $1220 / 2833(43.1)$ \\
\hline \multirow{2}{*}{ Feedback request } & no & $2833 / 3439(82.4)$ & $1613 / 2833(56.9)$ & $23 / 278(8.3)$ \\
\hline
\end{tabular}

*statistically significant values $(p<0.05)$ 
obtained from a gynaecologist significantly increased the chances of a pregnant woman registering at a dental clinic $(\mathrm{OR}=5.20$ (4.05-6.67); $\mathrm{p}<0.001)$, which was even higher when dental consultation feedback about oral health status was requested $(\mathrm{OR}=2.19(1.3-3.66) ; \mathrm{p}=0.003)$.

\section{DISCUSSION}

The World Health Organization, as well as the societies of gynaecologists, obstetricians, and dentists, emphasize that oral health is an integral part of medical care during pregnancy [18]. Unfortunately, many women do not report to the dentist during pregnancy. Studies have shown that among 801 pregnant women in the United States, only $57 \%$ of them attended to the dental office [19]. Results of a nationwide survey conducted in the framework of the "Prevention Program for Alcohol, Tobacco and Other Psychoactive Drugs" involving a group of 2749 postpartum women showed similar attendance to their dentist appointments. Only $51.2 \%$ of respondents had dental examinations during pregnancy [20]. In Australia, only $30 \%$ of women went to the dentist [21, 22].

There are many socio-demographic factors involved, such as poor education and pro-health awareness, or low economic status, which affect the attendance of women during pregnancy to the dentist [23-26]. Our results are in line with the observations of other authors. However, we show that the influence of sociodemographic factors is weakened when it is pregnant patient's gynaecologist that refers her to a dental appointment. Unfortunately, only $17.6 \%$ of the women we surveyed received such referrals, and even fewer women were asked to provide feedback on their current oral health status after the dental consultation. The literature does not provide information on the extent to which the involvement of gynaecologists results in the reporting of pregnant women to the dentist. The importance of the gynaecologist's cooperation with the dentist was confirmed by the effectiveness of the program implemented in Oregon. The increase in the number of dental referrals made by gynaecologists and the education of women about oral health has increased the proportion of women reporting to dentists during pregnancy from $8.8 \%$ to $55.8 \%$ [27].

Surveys conducted in other regions of the world have shown that visits to the dentist during pregnancy are suggested by $44 \%$ to $93.9 \%$ of specialists [28-32]. A relation between the referral of pregnant women to the dentist and knowledge about the impact of oral health on pregnancy has been shown [31]. According to Reddy et al., gynaecologists have the knowledge and proper approach to preventing oral diseases. In their study, most of the surveyed physicians (93.9\%) thought that a routine visit to the dentist was important. These doctors referred pregnant women to the dentist and $69 \%$ of them conducted oral health examinations of their patients. As many as $94.6 \%$ of surveyed physicians believe that gynaecologists fill an important role in preventing oral diseases and $91.8 \%$ are interested in broadening their knowledge about oral disease prevention. However, other researchers have obtained contradicting results [30, 32-35]. Studies conducted in France have shown that gynaecologists and midwives have insufficient knowledge about oral health, oral disease implications during pregnancy, and dental procedures during this period [33]. According to Morgan et al., only $46 \%$ of gynaecologists ask women about their oral health and $31 \%$ provide information on this aspect [30]. In turn, a survey among gynaecologists and midwives in the US revealed that $80 \%$ of them respect that perinatal oral health is an important consideration for optimal prenatal care. At the same time, only 53\% reported having specific oral health questions on their intake documents. Only 35\% discussed oral health, 29\% performed an oral cavity exam and $42 \%$ recommended an oral health assessment by a dentist. These data show the dichotomy of care in obstetrics. Unfortunately, only $10 \%$ of gynaecologists and $14 \%$ of midwives have established professional relationships with dental providers [35].

A number of physicians still consider it dangerous to perform certain diagnostic or therapeutic procedures during pregnancy, such as dental radiography and local anaesthesia [29]. In a study by Al-Habanesh et al., $81 \%$ of the doctors agreed that pregnancy caused gingival inflammation, but $88 \%$ advised patients to postpone treatment until after delivery. It is important to note that women in the postpartum period focus on the care of the newborn, which makes it difficult to benefit from dental care. A woman should be referred to a dentist during the first trimester of pregnancy. This will ensure an adequate time for the necessary preventive procedures and treatment. This is especially important if there is a need to have several dental appointments. An additional benefit for pregnant women is the extended reimbursement of publicly-funded dental care for pregnant and postpartum women. Unfortunately, studies conducted among pregnant women point to the existence of a considerable need for prevention and treatment of oral diseases. About $60 \%$ of them suffer from gingivitis, and more than $70 \%$ of them have active, untreated carious lesions [17].

\section{CONCLUSIONS}

A greater involvement of gynaecologists in the promotion of perinatal oral health is essential. The results obtained indicate that referring a pregnant woman to a dentist, in addition to asking for associated feedback on current oral health, increases the likelihood of a woman to attend dental appointments. 


\section{REFERENCES}

1. Hartnett E, Haber J, Krainovich-Miller B, et al. Oral Health in Pregnancy. J Obstet Gynecol Neonatal Nurs. 2016; 45(4): 565-573, doi: 10.1016/j. jogn.2016.04.005, indexed in Pubmed: 27281467.

2. Offenbacher S, Katz V, Fertik G, et al. Periodontal infection as a possible risk factor for preterm low birth weight. J Periodontol. 1996; 67(10 Suppl): 1103-1113, doi: 10.1902/jop.1996.67.10s.1103, indexed in Pubmed: 8910829.

3. Offenbacher S, Beck JD. Periodontitis: a potential risk factor for spontaneous preterm birth. Compend Contin Educ Dent. 2001; 22(2 Spec No): 17-20, indexed in Pubmed: 19248253

4. Mazor M, Wiznitzer A, Maymon E, et al. Changes in amniotic fluid concentrations of prostaglandins E2 and F2 alpha in women with preterm labor. Isr J Med Sci. 1990; 26(8): 425-428, indexed in Pubmed: 2401604.

5. Offenbacher S, Lieff S, Boggess KA, et al. Maternal periodontitis and prematurity. Part I: Obstetric outcome of prematurity and growth restriction. Ann Periodontol. 2001; 6(1): 164-174, doi: 10.1902/annals.2001.6.1.164, indexed in Pubmed: 11887460.

6. Dasanayake AP. Poor periodontal health of the pregnant woman as a risk factor for low birth weight. Ann Periodontol. 1998; 3(1): 206-212, doi: 10.1902/annals.1998.3.1.206, indexed in Pubmed: 9722704.

7. Davenport ES, Williams CE, Sterne JA, et al. The East London Study of Maternal Chronic Periodontal Disease and Preterm Low Birth Weight Infants: study design and prevalence data. Ann Periodontol. 1998; 3(1): 213-221, doi: 10.1902/annals.1998.3.1.213, indexed in Pubmed: 9722705.

8. Sadatmansouri S, Sedighpoor N, Aghaloo M. Effects of periodontal treatment phase I on birth term and birth weight. J Indian Soc Pedod Prev Dent. 2006; 24(1): 23-26, indexed in Pubmed: 16582527.

9. Kawashita Y, Kitamura M, SaitoT. Early childhood caries. Int J Dent. 2011; 2011: 725320, doi: 10.1155/2011/725320, indexed in Pubmed: 22007218.

10. Mitchell SC, Ruby JD, Moser S, et al. Maternal transmission of mutans Streptococci in severe-early childhood caries. Pediatr Dent. 2009; 31(3): 193-201, indexed in Pubmed: 19552223.

11. Zanata RL, Navarro MF, Pereira JC, et al. Effect of caries preventive measures directed to expectant mothers on caries experience in their children. Braz Dent J. 2003; 14(2): 75-81, indexed in Pubmed: 12964648.

12. Berkowitz RJ. Causes, treatment and prevention of early childhood caries: a microbiologic perspective. J Can Dent Assoc. 2003; 69(5): 304-307, indexed in Pubmed: 12734024.

13. Berkowitz RJ. Acquisition and transmission of mutans streptococci. J Calif Dent Assoc. 2003; 31(2): 135-138, indexed in Pubmed: 12636317.

14. Ersin NK, Eronat N, Cogulu D, et al. Association of maternal-child characteristics as a factor in early childhood caries and salivary bacterial counts. J Dent Child (Chic). 2006; 73(2): 105-111, indexed in Pubmed: 16948372.

15. Chaffee BW, Gansky SA, Weintraub JA, et al. Maternal oral bacterial levels predict early childhood caries development. J Dent Res. 2014; 93(3): 238-244, doi: 10.1177/0022034513517713, indexed in Pubmed: 24356441.

16. Warren JJ, Weber-Gasparoni K, Marshall TA, et al. A longitudinal study of dental caries risk among very young low SES children. Community Dent Oral Epidemiol. 2009; 37(2): 116-122, doi: 10.1111/j.1600-0528.2008.00447.x, indexed in Pubmed: 19046332.

17. Dacyna N, Trzaska M, Zawadzka A, et al. Wskaźniki wysokiej liczebności bakterii kariogennych u kobiet ciężarnych. Nowa Stomatol. 2017; 2: 11-20.

18. Petersen PE. World Health Organization global policy for improvement of oral health--World Health Assembly 2007. Int Dent J. 2008; 58(3): 115-121, indexed in Pubmed: 18630105.

19. Cigna Corporation. Healthy smiles for mom and baby: Insights into expecting and new mothers' oral health habits. 2015. https://www. cigna.com/assets/docs/newsroom/cigna-study-healthy-smiles-for-mom-and-baby-2015.pdf.
20. Badania ankietowe rodzących kobiet. WŻukiewicz-SobczakW, Paprzycki P (eds.) Raport "Zachowania zdrowotne kobiet w ciąży" Instytut Medycyny Wsi im. Witolda Chodźki, Lublin 2013, 103- 145 Lublin, 2013. Raport. http://zdrowiewciazy.pl/pdf/publikacje/raport_zachowania_zdrowotne_kobiet_w_ciazy.pdf (Lublin 2013).

21. Thomas NJ, Middleton PF, Crowther CA. Oral and dental health care practices in pregnant women in Australia: a postnatal survey. BMC Pregnancy Childbirth. 2008; 8: 13, doi: 10.1186/1471-2393-8-13, indexed in Pubmed: 18426558

22. George A, Johnson M, Blinkhorn A, et al. The oral health status, practices and knowledge of pregnant women in south-western Sydney. Aust Dent J. 2013; 58(1): 26-33, doi: 10.1111/adj.12024, indexed in Pubmed: 23441789.

23. Azofeifa A, Yeung LF, Alverson CJ, et al. Oral health conditions and dental visits among pregnant and nonpregnant women of childbearing age in the United States, National Health and Nutrition Examination Survey, 1999-2004. Prev Chronic Dis. 2014; 11: E163, doi: 10.5888/pcd11.140212, indexed in Pubmed: 25232750.

24. Hwang SS, Smith VC, McCormick MC, et al. Racial/ethnic disparities in maternal oral health experiences in 10 states, pregnancy risk assessment monitoring system, 2004-2006. Matern Child Health J. 2011; 15(6): 722 729, doi: 10.1007/s10995-010-0643-2, indexed in Pubmed: 20652385.

25. Le $M$, Riedy $C$, Weinstein $P$, et al. An intergenerational approach to ora health promotion: Pregnancy and utilization of dental services. J Dent Child (Chick). 2009; 76(1): 46-52, indexed in Pubmed: PMC2891449.

26. Marchi KS, Fisher-Owen SA, Weintraub JA, et al. Most pregnant women in California do not receive dental care: findings from a population-based study. Public Health Rep. 2010; 125(6): 831-842, doi: 10.1177/003335491012500610, indexed in Pubmed: 21121228.

27. Milgrom P, Ludwig S, Shirtcliff RM, et al. Providing a dental home for pregnant women: a community program to address dental care access--a brief communication. J Public Health Dent. 2008; 68(3): 170-173, indexed in Pubmed: 18843805.

28. Prakash S, Reddy S, Lakshminarayan N. Gynecologists' concerns about oral diseases - A step to interdisciplinary approach. International Journal of Oral Health Sciences. 2014; 4(2): 58-62, doi: 10.4103/22316027.165100 .

29. Hashim R, Akbar M. Gynecologists' knowledge and attitudes regarding oral health and periodontal disease leading to adverse pregnancy outcomes. J Int Soc Prev Community Dent. 2014; 4(Suppl 3): S166-S172, doi: 10.4103/2231-0762.149028, indexed in Pubmed: 25625074.

30. Morgan MA, Crall J, Goldenberg RL, et al. Oral health during pregnancy. J Matern Fetal Neonatal Med. 2009; 22(9): 733-739, doi: 10.3109/14767050902926954, indexed in Pubmed: 19488943.

31. Suri V, Rao NC, Aggarwal N. A study of obstetricians'knowledge, attitudes and practices in oral health and pregnancy. Educ Health (Abingdon). 2014; 27(1): 51-54, doi: 10.4103/1357-6283.134313, indexed in Pubmed: 24934944.

32. Al-Habashneh R, Aljundi SH, Alwaeli HA. Survey of medical doctors' attitudes and knowledge of the association between oral health and pregnancy outcomes. Int J Dent Hyg. 2008; 6(3): 214-220, doi: 10.1111/j.1601-5037.2008.00320.x, indexed in Pubmed: 18768026.

33. Boutigny $\mathrm{H}$, de Moegen $\mathrm{ML}$, Egea $\mathrm{L}$, et al. Oral Infections and Pregnancy: Knowledge of Gynecologists/Obstetricians, Midwives and Dentists. Oral Health Prev Dent. 2016; 14(1): 41-47, doi: 10.3290/j.ohpd.a34376, indexed in Pubmed: 26106653.

34. Patil S, Thakur R, K M, et al. Oral Health Coalition: Knowledge, Attitude, Practice Behaviours among Gynaecologists and Dental Practitioners. J Int Oral Health. 2013; 5(1): 8-15, indexed in Pubmed: 24155572.

35. Wilson EH, Farrell C, Zielinski RE, et al. Obstetric provider approach to perinatal oral health. J Matern Fetal Neonatal Med. 2017; 30(9): 1089-1091, doi: 10.1080/14767058.2016.1204291, indexed in Pubmed: 27325046. 